but is necessary, given the fact that ants, bees and wasps include some of the most beneficial insects on Earth and provide crucial ecosystem services, such as pollination. Thus, their extinction could have a widespread impact.

\section{References}

1 Hedrick, P.W. et al. (1996) Directions in conservation biology: comments on Caughley. Conserv. Biol. 10, 1312-1320

2 Hedrick, P.W. (2001) Conservation genetics: where are we now? Trends Ecol. Evol. 16, 629-636

3 Caughley, G. (1994) Directions in conservation biology. J. Anim. Ecol. $63,215-244$

4 DeMauro, M.M. (1993) Relationship of breeding system to rarity in the lakeside daisy (Hymenoxys acaulis var. glabra). Conserv. Biol. 7, $542-550$

5 Edwards, S.V. and Potts, W.K. (1996) Polymorphism of genes in the major histocompatibility complex (MHC): implications for conservation genetics of vertebrates. In Molecular Genetic Approaches in Conservation (Smith, T.B. and Wayne, R.K., eds), pp. 214-237, Oxford University Press

6 Pamilo, P. and Crozier, R.H. (1997) Population biology of social insect conservation. Mem. Mus. Vict 56, 411-419

7 Zayed, A. and Packer, L. (2005) Complementary sex determination substantially increases extinction proneness of haplodiploid populations. Proc. Natl. Acad. Sci. U. S. A. 102, 10742-10746

8 Gilpin, M.E. and Soulé, M.E. (1986) Minimum viable populations: Processes of species extinction. In Conservation Biology: The Science of Scarcity and Diversity (Soulé, M.E., ed.), pp. 19-34, Sinauer Associates

9 Carvalho, G.A. (2001) The number of sex alleles (CSD) in a bee population and its practical importance (Hymenoptera: Apidae). J. Hymenopt. Res. 10, 10-18
10 Tallmon, D.A. et al. (2004) The alluring simplicity and complex reality of genetic rescue. Trends Ecol. Evol. 19, 489-496

11 Beye, M. et al. (1999) Unusually high recombination rate detected in the sex locus region of the honey bee (Apis mellifera). Genetics 153, $1701-1708$

12 Woyke, J. (1963) What happens to diploid drone larvae in a honeybee colony? J. Apic. Res. 2, 73-75

13 Castric, V. and Vekemans, X. (2004) Plant self-incompatibility in natural populations: a critical assessment of recent theoretical and empirical advances. Mol. Ecol. 13, 2873-2889

14 Young, A.G. et al. (2000) Genetic erosion, restricted mating and reduced viability in fragmented populations of the endangered grassland herb: Rutidosis leptorrhynchoides. In Genetics, Demography and Viability of Fragmented Populations (Young, A.G. and Clarke, G.M., eds), pp. 335-359, Cambridge University Press

15 Garrigan, D. and Hedrick, P.W. (2003) Perspective: detecting adaptive molecular evolution, lessons from the MHC. Evolution 57, 1707-1722

16 Satta, Y. et al. (1994) Intensity of natural selection at the major histocompatibility complex loci. Proc. Natl. Acad. Sci. U. S. A. 91, $7184-7188$

17 Cook, J.M. and Crozier, R.H. (1995) Sex determination and population biology in the Hymenoptera. Trends Ecol. Evol. 10, 281-286

18 Buther, R.D.J. et al. (2000) Complementary sex determination in the genus Diadegma (Hymenoptera: Ichneumonidae). J. Evol. Biol. 13, 593-606

19 Zayed, A.D. et al. (2004) Use of diploid male frequency data as an indicator of pollinator decline. Proc. R. Soc. B 271, S9-S12

20 Liebert, A.E. et al. (2004) Triploid females and diploid males: underreported phenomena in Polistes wasps? Insect Soc. 51, 205-211

0169-5347/\$ - see front matter (c) 2005 Elsevier Ltd. All rights reserved. doi:10.1016/j.tree.2005.11.014

\title{
Kin selection is the key to altruism
}

\author{
Kevin R. Foster ${ }^{1,2}$, Tom Wenseleers ${ }^{2,3}$ and Francis L.W. Ratnieks ${ }^{2,4}$ \\ ${ }^{1}$ Laboratory of Ecological and Evolutionary Dynamics, Department of Biological and Environmental Sciences, \\ University of Helsinki, Helsinki, 00014, Finland \\ ${ }^{2}$ Wissenschaftskolleg zu Berlin, Institute for Advanced Study, Berlin, 14193, Germany \\ ${ }^{3}$ Zoological Institute, University of Leuven, B-3000 Leuven, Belgium \\ ${ }^{4}$ Laboratory of Apiculture and Social Insects, Department of Animal and Plant Sciences, University of Sheffield, \\ Sheffield, UK, S10 2TN
}

Kin selection theory, also known as inclusive fitness theory, has been the subject of much debate and misunderstanding. Nevertheless, the idea that relatedness among individuals can drive the evolution of altruism has emerged as a central paradigm in evolutionary biology. Or has it? In two recent articles, E.O. Wilson argues that kin selection should no longer be considered the main explanation for the evolution of altruism in insect societies. Here, we discuss what these articles say about kin selection and how it relates to the theory. We conclude that kin selection remains the key explanation for the evolution of altruism in eusocial insects.

Corresponding author: Foster, K.R. (krfoster@rice.edu).

Available online 20 December 2005
What is kin selection?

The first glimmers of kin selection theory (see Glossary) were comments made by Haldane and Fisher that kinship can be important in social actions ([1,2] and refs therein). However, it was Hamilton who showed the general importance of relatedness in evolution [1]. His theory takes its most accessible form in the inequality known as Hamilton's rule, which predicts that altruistic action will be favoured when $b r>c$, where $c$ and $b$ are the cost and benefit to actor and recipient, respectively, and $r$ is their relatedness. Hamilton called his new and general principle of natural selection 'inclusive fitness theory' [1], but it is often known by the term 'kin selection', coined by Maynard Smith ([3] and refs therein). 


\section{Glossary}

Altruism: action that, on average, decreases the lifetime direct fitness of an actor and benefits one or more recipients; also 'strong' altruism [10].

Altruism (weak): cooperative investment in a group by a group member, where the cost to the individual is outweighed by the feedback benefit to the individual from group membership (decreases within-group fitness of an actor but increases its fitness in the population) [10].

Cooperation: action that benefits one or more recipients.

Direct fitness: fitness from personal reproduction.

Eusociality: social groups in which some individuals specialise in work or help to enhance the direct reproduction of others (see [3] for a full definition).

Group selection: selection caused by the differential productivity and/or survival of whole groups, including colonies, demes, species and communities. Haplodiploidy hypothesis: idea that the $3 / 4$ relatedness among full sisters in haplodiploids predisposes them to eusociality with female workers $[1,3,5,13]$. Inclusive fitness: direct plus indirect fitness [3,13,15].

Indirect fitness: fitness component received from effects on the reproduction of relatives.

Kin selection: selection affected by relatedness among individuals (also used as an abbreviation of kin selection theory) $[3,12,13]$.

Kin selection or inclusive fitness theory: theory that models social traits with a focus on the individual (group effects are often implicit) and uses relatedness coefficients to capture effects of genetic correlations among individuals $[1,3,13]$. Relatedness: genetic correlation among individual loci or organisms $[3,12,13]$. Trait-group selection theory (also multi-level selection or levels of selection theory): theory that models social traits in terms of effects on the individual and the group; it often uses between-group genetic variance as an equivalent to relatedness $[10,14]$

\section{The fall of kin selection?}

E.O. Wilson [2] and E.O. Wilson and Hölldobler [4] criticise the kin selection explanation for altruism on several grounds (Table 1). E.O. Wilson [2] emphasises problems with one idea that arose from kin selection thinking, known as the haplodiploidy hypothesis [1], and argues that kin selection is similarly limited. In addition, both papers [2,4] criticise kin selection because it neglects ecological factors, predicts conflict rather than altruism and does not account for important colony-level effects. It is also argued that, contrary to kin selection predictions, altruism can evolve without relatedness. Alternatives to kin selection are provided in the form of a modified Hamilton's rule [2] and a scenario where having a 'eusocial allele' rather than high family relatedness causes individuals to behave altruistically [4]. Here, we show that E.O. Wilson's criticisms are based upon commonly made errors in either the definition or application of kin selection theory (Table 1). Uncovering these errors makes it clear that his ideas are not true alternatives to kin selection theory, and that the E.O.
Wilson and Hölldobler [4] scenario for the origin of eusociality is probably incorrect.

\section{The haplodiploidy hypothesis and kin selection theory are not equivalent}

In his 1964 papers [1], Hamilton suggested that the unusually high relatedness among full sisters $(r=0.75)$ in the haplodiploid Hymenoptera (bees, ants and wasps) relative to that among diploids $(r=0.5)$ helps to explain why eusociality is so frequent in the Hymenoptera. However, this idea, known as the 'haplodiploidy' or ${ }^{3} 3 / 4$ relatedness' hypothesis [5], neglected the lower relatedness of sisters to brothers $(r=0.25)$ in haplodiploids. When averaged out, the relatedness of daughter Hymenoptera to their full siblings is the same as it is to their offspring $(r=0.5)$, as seen in diploids. As a result, the haplodiploidy hypothesis has, for many years, been considered less important than it was initially $[3,5,6]$. E.O. Wilson takes this to mean that kin selection theory is similarly limited [2]. However, the haplodiploidy hypothesis is just one application of the broader theory of kin selection. Its limitations have no bearing on either the validity of kin selection theory or the key insight that relatedness can select for altruistic actions [3,5]. This is well illustrated by recent evidence for kin selection in the evolution of helping in vertebrates, which, as diploids, are not subject to the haplodiploidy hypothesis [7].

\section{Kin selection theory predicts that both ecology and relatedness are important}

Wilson criticises kin selection on the grounds that environmental or ecological factors can be more important than is relatedness in determining social actions [2,4]. However, kin selection does not say that relatedness will be more important than ecology. Hamilton's rule shows that environmental factors causing a high benefit:cost ratio will favour altruism, provided that the relatedness between the actor and recipient is positive [1,3]. Relatedness does not have to be high for altruism to evolve, but it must be $>0$. The point is that relatedness and environmental or ecological factors are both essential parts of the kin selection perspective.

Table 1. Common fallacies concerning kin selection (or inclusive fitness) theory

\begin{tabular}{|c|c|c|c|}
\hline Fallacy & Refs & Reality & Refs \\
\hline $\begin{array}{l}\text { Kin selection is the } 3 / 4 \text { relatedness or haplodiploidy } \\
\text { hypothesis }\end{array}$ & {$[2]$} & $\begin{array}{l}\text { The haplodiploidy hypothesis is just one idea arising } \\
\text { from kin selection theory }\end{array}$ & {$[3,5,6]$} \\
\hline $\begin{array}{l}\text { Kin selection suggests that relatedness is the dominant } \\
\text { force in the evolution of social actions }\end{array}$ & {$[2,4]$} & Costs and benefits can be dominant effects & {$[3,11]$} \\
\hline $\begin{array}{l}\text { Kin selection predicts conflict so it cannot favour } \\
\text { altruism }\end{array}$ & {$[2,4]$} & $\begin{array}{l}\text { For intermediate levels of relatedness }(0<r<1) \text {, the } \\
\text { potential for conflict and altruism are predicted }\end{array}$ & {$[3,6,9,11,15]$} \\
\hline $\begin{array}{l}\text { Support for kin selection from the study of reproduc- } \\
\text { tive conflict has no bearing on the evolution of altruism }\end{array}$ & [8] & $\begin{array}{l}\text { Kin selection is a general theory. Support in one area } \\
\text { strengthens the theory and its application in other areas } \\
\text { where it is relevant }\end{array}$ & {$[15]$} \\
\hline Kin selection assumes no colony-level effects & {$[2,4,8]$} & $\begin{array}{l}\text { Kin selection models include colony-level effects, } \\
\text { sometimes implicitly and sometimes explicitly }\end{array}$ & {$[3,9,11]$} \\
\hline $\begin{array}{l}\text { Kin selection is incompatible with trait-group selection } \\
\text { thinking }\end{array}$ & {$[2,4]$} & $\begin{array}{l}\text { The two frameworks are complementary and fully } \\
\text { compatible }\end{array}$ & {$[12-14]$} \\
\hline $\begin{array}{l}\text { Relatedness }(r) \text { and kin selection only apply to family } \\
\text { relatedness caused by recent common ancestry }\end{array}$ & {$[4]$} & $\begin{array}{l}\text { The } r \text { in Hamilton's rule applies to all forms of genetic } \\
\text { correlation among individuals, including among loci } \\
\text { and among organisms }\end{array}$ & {$[1,12,13]$} \\
\hline
\end{tabular}


Kin selection theory predicts cooperation and conflict

Another fallacy is to assume that, because kin selection theory predicts reproductive conflicts among related individuals ('dissolutive effects' $[2,4]$ ), it cannot simultaneously explain cooperation and altruism. Alonso and Schuck-Paim made a similar mistake [8] (Table 1). Studies of reproductive conflicts have resulted in some powerful tests of kin selection theory, particularly in the social insects [9], because extant conflicts are more easily studied than the origins of eusociality [3]. However, the predictions that kin selection theory makes about conflict do not undermine the validity of its predictions relating to cooperation. Kin selection predicts the potential not only for conflict within insect societies, because relatedness among individuals is usually $<1$ (i.e. they are not clones), but also for altruism, because relatedness is usually $>0$ (i.e. they are a family): consider the worker:queen production ratio in Melipona bees, where higher relatedness results in more female larvae altruistically developing into workers rather than into queens [9].

\section{Group selection does not select for altruism without kin selection}

E.O. Wilson argues that it is selection at the colony level rather than kin selection that drives altruism in insect societies. Colony-level effects can select for cooperation without kin selection, but not for true altruism. In his trait-group selection models, D.S. Wilson [10] showed that investment in a group of nonrelatives can be selected when, by helping the group, the actor receives a feedback benefit to its own reproduction ('weak altruism'). It is this effect that E.O. Wilson [2] captures in his expanded Hamilton's rule: $b_{k} r+b_{e}>c$, where $b_{k}$ is the benefit to kin and $b_{e}$ is the benefit of colony-level selection. More explicitly (Equation I):

$$
\begin{gathered}
\frac{b}{n}(n-1) r+\left(\frac{b}{n}\right) \cdot 1>c \\
\begin{array}{c}
\text { Individual } \\
\text { benefit }
\end{array}
\end{gathered}
$$

where $n$ is group size, $b$ is the group benefit of which each individual gets a share $b / n$, and $c$ is the individual cost. The individual benefit term contains the relatedness of the actor to itself, $r_{\text {self }}=1$ and is equivalent to the benefit from 'colony-level selection in [2]. Weak altruism can evolve without relatedness when the individual benefit term outweighs the individual cost, $c$ ('strong group selection' [10]). However, for true altruism, the cost is greater than the individual benefit, because altruism, by definition, is individually costly. It is clear, therefore, that the altruism of worker insects, which frequently have zero reproduction, can only be selected if relatedness is positive [10].

More generally, the presence of colony-level effects is not evidence against kin selection, as E.O. Wilson [2], E.O. Wilson and Hölldobler [4] and others [8] suggest. Trait-group selection models can sometimes highlight colony-level effects in a clearer way than can a kin selection model, but at a deeper level the two frameworks have long been known to be simply different ways of formalising the same problem [3,12-14]. Kin selection models frequently contain colony-level effects $[3,9,11]$ just as traitgroup selection models often contain relatedness in the form of between-group genetic variance $[3,12,14]$.

\section{Can altruism ever evolve without relatedness?}

Inclusive fitness theory does not predict that altruism can evolve without relatedness. But neither does any other theory if we mean altruism in the strict sense used by E.O. Wilson [2] and E.O. Wilson and Hölldobler [4]. It could be argued that manipulation sometimes forces 'altruism' without relatedness, and manipulation does contribute to worker sterility in insects $[3,9,15]$. However, behaviours resulting entirely from manipulation, such as a host giving resources to a parasite, are not altruistic adaptations. Indeed, the discovery of true altruism that evolved in the absence of relatedness would be strong evidence against kin selection theory, paralleling Darwin's statement that altruism between species would reject natural selection: 'If it could be proved that any part of the structure of any one species had been formed for the exclusive good of another species, it would annihilate my theory...' [16].

We know of no such examples for either kin selection or natural selection. It is perhaps surprising, therefore, that both of Wilson's papers claim that altruism can evolve without relatedness [2,4]. However, this is because 'relatedness' and 'kin selection' are defined to apply only when relatedness is caused by recent common ancestry, such as that between siblings. The term 'kin selection' is sometimes used in this way, but to the extent that kin selection is synonymous with Hamilton's work [6], the theory is much broader. Crucially, Hamilton showed that relatedness can arise without recent common ancestry. For example, he described the hypothetical example of a supergene that can directly recognise and help other copies of itself in other individuals [6], later dubbed a green-beard gene by Dawkins [5]. Although phrased in the terminology of trait-group selection, the 'eusocial allele' model of Wilson and Hölldobler [4] is essentially a restatement of this idea.

In general, non-zero relatedness is generated whenever genes are correlated across individuals, and it is in this sense that relatedness is used by those that develop kin selection theory $[1,5,12,13,15]$ (Table 1). It can then be seen that the theoretical papers that Wilson and Hölldobler [4] cite for altruism without relatedness are also compatible with kin selection thinking. One paper shows that altruism can evolve when nonrandom interactions generate relatedness in nonfamily groups [14], a point made earlier by Hamilton [12,14]. In another, relatedness arises through tag-based recognition that is similar to green-beard recognition [17]. In sum, relatedness is always required for altruism to evolve.

\section{Conclusion}

Hamilton's early work made it clear that altruism can evolve owing to relatedness caused by common ancestry and relatedess caused by other means [6]. That said, even if we restrict relatedness to the 'narrow sense' of Wilson 
and Hölldobler [4], which considers only recent common ancestry, kin selection remains the best explanation for altruism in eusocial groups because most are families $[3,6]$. Unrelated ant and wasp queens do found nests together $[2,4]$, but this is a mutualistic interaction that can work at $r=0$ [3]. Workers are typically related to the individuals that they altruistically help. Even when relatedness is close to zero in unicolonial ants [3], relatedness was $>0$ when the altruistic worker caste first evolved. Furthermore, theory predicts that family relatedness is more likely to produce stable altruism than are other forms of relatedness, such as green-beard genes [3]. This suggests that it is selection acting through family relatedness that explains the altruism of eusocial species. We are unconvinced by E.O. Wilson's recent ideas, but are in full agreement with his earlier view: 'How can altruism, which by definition reduces personal fitness, possible evolve by natural selection? The answer is kinship...' [18].

\section{Acknowledgements}

We thank Andrew Bourke, Joan Strassmann, David Queller, Andy Gardner, Hanna Kokko, Lotta Sundström, Emma Vitikainen and an anonymous referee for helpful comments.

\section{References}

1 Hamilton, W.D. (1964) The genetical evolution of social behaviour. I \& II. J. Theor. Biol. 7, 1-52

2 Wilson, E.O. (2005) Kin selection as the key to altruism: its rise and fall. Soc. Res. 72, 159-168

3 Bourke, A.F.G. and Franks, N.R. (1995) Social Evolution in Ants, Princeton University Press
4 Wilson, E.O. and Hölldobler, B. (2005) Eusociality: origin and consequences. Proc. Natl. Acad. Sci. U. S. A. 102, 13367-13371

5 Dawkins, R. (1989) The Selfish Gene, 2nd edn, Oxford University Press

6 Queller, D.C. and Strassmann, J.E. (1998) Kin selection and social insects. Bioscience 48, 165-175

7 Griffin, A.S. and West, S.A. (2003) Kin discrimination and the benefit of helping in cooperatively breeding vertebrates. Science 302, 634-636

8 Alonso, W.J. and Schuck-Paim, C. (2002) Sex-ratio conflicts, kin selection, and the evolution of altruism. Proc. Natl. Acad. Sci. U. S. A. 99, 6843-6847

9 Ratnieks, F.L.W. et al. (2006) Conflict resolution in insect societies. Annu. Rev. Entomol. 51, 581-608

10 Wilson, D.S. (1990) Weak altruism, strong group selection. Oikos 59, $135-140$

11 Foster, K.R. (2004) Diminishing returns in social evolution: the not-sotragic commons. J. Evol. Biol. 17, 1058-1072

12 Hamilton, W.D. (1975) Innate social aptitudes in man: an approach from evolutionary genetics. In Biosocial Anthropology (Fox, R., ed.), pp. 133-155, John Wiley \& Sons

13 Frank, S.A. (1998) The Foundations of Social Evolution, Princeton University Press

14 Wilson, D.S. and Dugatkin, L.A. (1997) Group selection and assortative interactions. Am Nat 149, 336-351

15 Bourke, A.F.G. (2005) Genetics, relatedness and social behaviour in insect societies. In Insect Evolutionary Ecology (Fellowes, M. et al., eds), pp. 1-30, CABI Publishing

16 Darwin, C.R. (1859) On the Origin of Species, John Murray

17 Roberts, G. and Sherratt, T.N. (2002) Behavioural evolution - does similarity breed cooperation? Nature 418, 499-500

18 Wilson, E.O. (1975) Sociobiology: The New Synthesis, Harvard Press

0169-5347/\$ - see front matter (C) 2005 Elsevier Ltd. All rights reserved. doi:10.1016/j.tree.2005.11.020

\section{Molecular cryptozoology meets the Sasquatch}

\section{Dave Coltman and Corey Davis}

Department of Biological Sciences, University of Alberta, Edmonton, AB, Canada, T6G 2E9

Most mainstream scientists believe that few species of large mammal remain to be discovered. Nevertheless, there are countless unverified reports of a large, non-human, bipedal primate from Asia (the 'Yeti') and North America ('Sasquatch' or 'Bigfoot'). Thus far, none of these reports has been convincingly verified by modern scientific methods [1]. However, new species inhabiting remote areas are occasionally described that were previously known only from local and traditional knowledge. The most recently described large mammal could be the sao la Pseudoryx nghetinhensis, which became known to science in 1992 from three sets of horns found in the possession of hunters in the Vu Quang Nature Reserve in Vietnam [2]. Subsequent surveys and the morphometric and DNA analysis of $>20$ specimens revealed that the sao la was a previously undescribed 100$\mathrm{kg}$ bovid distinct from all described genera. More recently, in

Corresponding author: Coltman, D. (dcoltman@ualberta.ca).

Available online 23 November 2005
2003 a new species of African monkey (Lophocebus kipunji) was discovered in southern Tanzania, based on sightings, photographs and recorded distinctive vocalizations [3]. Discoveries such as these fuel hope in the cryptozoology community for the existence of more enigmatic creatures, such as the Sasquatch.

Several high-profile Sasquatch sightings have recently been reported in Canada. In April 2005, a Manitoba ferry operator videotaped a large, dark, indistinct creature moving along a riverbank, which made international news. In July 2005, nine residents of Teslin, Yukon, witnessed through a kitchen window a large bipedal animal moving through the brush. The next morning, they collected a tuft of coarse, dark hair and also observed a footprint measuring $43 \mathrm{~cm}$ in length and $11.5 \mathrm{~cm}$ in width. The tuft of hair was sent to Philip Merchant, a wildlife technician of the Government of Yukon Department of Environment who, based on structural features, identified it as probably originating from bison Bison bison. We 